\title{
Trainee Impact on Procedural Complications: An Analysis of 967 Consecutive Flexible Bronchoscopy Procedures in an Interventional Pulmonology Practice
}

\author{
David R. Stather ${ }^{\mathrm{a}}$ Paul MacEachern ${ }^{\mathrm{a}}$ Alex Chee ${ }^{\mathrm{a}}$ Elaine Dumoulin ${ }^{\mathrm{b}}$ \\ Alain Tremblay ${ }^{a}$ \\ a Division of Respiratory Medicine, Department of Medicine, University of Calgary, Calgary, Alta., and \\ ${ }^{b}$ Department of Medicine, University of Sherbrooke, Sherbrooke, Que., Canada
}

\section{Key Words}

Bronchoscopy - Complications · Education .

Endobronchial ultrasound · Simulation · Training

\begin{abstract}
Background: Increased complications have been demonstrated in patients undergoing some medical procedures performed by trainees. Flexible bronchoscopy is generally considered a safe procedure; however, complications can include pneumothorax, bleeding and even death. Objectives: This study aimed to determine the impact of trainees during interventional pulmonology procedures on procedure time, sedation use and complications. Methods: A retrospective review of a quality improvement database from all consecutive medical procedures performed by an interventional pulmonologist (D.R.S.) at the University of Calgary, from July 1, 2007, to April 1, 2011. Results: Of 1,100 consecutive procedures during the study period, 967 were flexible bronchoscopies. A trainee participated in $82.2 \%$ of the procedures. Complications occurred in 38 patients (3.9\%). No death occurred. Significant differences were seen when a trainee participated in the procedure versus when no trainee partici-
\end{abstract}

pated for procedure length [50.81 vs. $32.49 \mathrm{~min}$, difference $18.32 \mathrm{~min}(95 \% \mathrm{Cl} 16.04-20.60), \mathrm{p}=0.001]$, dose of midazolam used [6.34 vs. $5.73 \mathrm{mg}$, difference $0.61 \mathrm{mg}$ ( $95 \% \mathrm{Cl} 0.15-$ $1.08), p=0.01]$, dose of propofol used [153.08 vs. $111.60 \mathrm{mg}$, difference $41.48 \mathrm{mg}(95 \% \mathrm{Cl} 21.81-61.15), \mathrm{p}=0.001$ ], as well as the number of complications [ 4.5 vs. $1.2 \%$, difference $3.3 \%, p=0.048]$. Conclusions: In an academic interventional pulmonology practice utilizing the apprenticeship model for procedural education, trainee participation in procedures can increase procedure time and the amount of sedation required, and result in increased complications. Medical procedural training methods that do not involve practicing on patients warrant further investigation in order to reduce the burden of procedural learning for patients.

Copyright $\odot 2013$ S. Karger AG, Basel

\section{Introduction}

Teaching procedural skills to trainees is vital to patient care in order to provide an adequate pool of trained physicians to meet the demand for specialized medical procedures. Procedural training experts have proposed that

\section{KARGER}

E-Mail karger@karger.com

www.karger.com/res
C 2013 S. Karger AG, Basel

0025-7931/13/0855-0422\$38.00/0
David R Stather, MD, FRCPC, FCCP

Division of Respiratory Medicine

Health Sciences Center, 3330 Hospital Drive NW

Calgary, AB T2N 4N1 (Canada)

E-Mail davestather@yahoo.ca 
patient-based teaching methods (also known as the apprenticeship model of procedural learning or the see-one, do-one and teach-one method) can result in increased erroneous diagnoses, increased patient discomfort and increased risk for procedure-related morbidity [1]. Higher complication rates have been demonstrated in inexperienced operators for central venous catheter insertion when the apprenticeship model of procedural learning is used [2], whereas improved clinical outcomes have been demonstrated with the use of simulation-based educational programs [3-5]. Although there is some limited evidence addressing the impact of trainees on outcomes of other medical procedures such as lumbar puncture [6] and thoracentesis [7], there remains a paucity of studies looking at how residency procedural training influences patient outcome [8].

Although it is generally considered a safe procedure, complications associated with flexible bronchoscopy include: fever, pneumonia, pneumothorax, laryngospasm, bleeding, infection, myocardial infarction, congestive heart failure, respiratory failure and even death [9-16]. Very few publications have looked at the impact of trainees on flexible bronchoscopy complications $[9,16]$. One study demonstrated that patients undergoing flexible bronchoscopy performed by junior trainees using the apprenticeship model of training have higher complication rates than senior trainees [16]. No study has yet compared flexible bronchoscopy complication rates in procedures with trainee participation versus procedures without trainee participation.

Interventional pulmonology procedures use advanced diagnostic and therapeutic techniques such as endobronchial ultrasound (EBUS) and electrocautery, and tend to be longer, more complicated pulmonology procedures. No study has looked at the rate of complications in an academic interventional pulmonology practice and the impact that trainees may have on complications. The aim of this study is to determine whether the participation of trainees during interventional pulmonology procedures leads to increased procedure time, increased sedation use and increased complications.

\section{Methods}

A retrospective analysis of a quality improvement database was performed on all consecutive pulmonology procedures performed by an interventional pulmonologist (D.R.S.) at the University of Calgary from July 1, 2007, to April 1, 2011. The study was approved by the Calgary Health Research Ethics Board (Ethics ID: E-23801). Prior to the start of this study, one of the authors
(D.R.S.) had completed approximately 800 flexible bronchoscopy procedures and 400 EBUS-transbronchial needle aspiration (TBNA) procedures.

\section{Inclusion Criteria and Database Design}

All consecutive patients undergoing an interventional pulmonology procedure during the study period were entered into a quality improvement database. The majority of data points were entered into an SPSS file at the time of the procedure (version 19.0; SPSS Inc., Chicago, Ill., USA), including any early complications. Six to 8 weeks following each procedure, the charts were reviewed, including follow-up visit notes for bronchoscopy results and additional notes from the referring physician or cancer center. Procedure results and any additional complications were then entered into the database.

\section{Description of Procedures}

Bronchoscopy procedures were performed in a dedicated bronchoscopy suite utilizing a 1T-160 or P-160 Olympus video bronchoscope (Olympus Canada, Markham, Ont., Canada) for the airway examination and a BF-UC160F-OL8 (EBUS bronchoscope; Olympus Canada) for the EBUS-TBNA procedure. Additional diagnostic or therapeutic techniques such as transbronchial biopsy, peripheral EBUS (UM-S20-20R; Olympus Canada), electromagnetic navigation bronchoscopy (ENB; superDimension Inc., Minneapolis, Minn., USA) and electrocautery were also used in some cases. Rapid onsite cytology was not used. Intermittent doses of intravenous midazolam were used in combination with intermittent small regular boluses of propofol to achieve moderate sedation (administered by the bronchoscopist), with lidocaine used for topical anesthesia of the airways. In the bronchoscopy suite, two dedicated bronchoscopy respiratory therapists assist with the procedure, patient monitoring and specimen collection in addition to the bronchoscopist and any trainees assisting with the procedure.

\section{Trainee Classification}

A trainee was defined as any physician in training who participated in the bronchoscopy procedure as the primary operator for the purpose of learning bronchoscopy. The trainees included interventional pulmonology fellows, general pulmonary fellows, thoracic surgery fellows and critical care fellows. All trainees participated in all aspects of the procedures, including EBUS-TBNA, ENB, peripheral EBUS and any biopsy techniques employed (i.e. when a trainee participated in the procedure they also performed the biopsies, including the transbronchial biopsies, EBUS-TBNA, ENB and peripheral EBUS biopsies). All trainees were trained via the apprenticeship model, meaning that they learned by practicing on patients. At the time of this study, there was no formal simulation-based bronchoscopy training available to the trainees.

\section{Assessment and Definition of Complications and Outcomes}

All patients undergoing transbronchial biopsies, ENB and peripheral EBUS had a chest radiograph and/or bedside ultrasound with confirmation of the sliding pleural sign within $2 \mathrm{~h}$ after the procedure. Any patient with no sliding pleural sign underwent a chest radiograph to confirm the presence of a pneumothorax. Fluoroscopy was not used in this study. Major bleeding was defined as $>5 \mathrm{ml}$ and requiring interruption of the procedure. Postbronchoscopic pneumonia was defined as fever (temperature $>38.5^{\circ} \mathrm{C}$ ) 
Table 1. Flexible bronchoscopy: patient demographics and procedure details

\begin{tabular}{|c|c|c|}
\hline Characteristics & No trainee $(n=172)$ & Trainee $(n=795)$ \\
\hline Female gender & $89(51.7 \%)$ & $409(51.4 \%)$ \\
\hline Age (means $\pm S D)$, years & $62.74 \pm 13.88$ & $61.33 \pm 14.73$ \\
\hline Inpatients $(\mathrm{p}<0.001)$ & $65(37.8 \%)$ & $190(23.9 \%)$ \\
\hline Clopidogrel (75 mg daily) treatment ${ }^{\mathrm{a}}$ & $2(1.2 \%)$ & $9(1.1 \%)$ \\
\hline Diagnostic bronchoscopy & $142(82.6 \%)$ & $644(81.0 \%)$ \\
\hline Final diagnosis of malignant disease $e^{c}$ & $108(62.7 \%)$ & $477(60.0 \%)$ \\
\hline
\end{tabular}

All comparisons were nonsignificant $(\mathrm{p}>0.05)$ except for inpatient status. Numbers $(\%)$ of patients are shown unless indicated otherwise.

${ }^{a}$ EBUS-TBNA only (no transbronchial biopsies, ENB or peripheral EBUS were performed on patients taking clopidogrel [41]).

${ }^{\mathrm{b}}$ Including pulmonary toilet, foreign body removal, electrocautery tumor debulking or cautery for hemoptysis/lesion treatment.

${ }^{\mathrm{c}}$ No diagnosis known or obtained in 55 of the 967 patients $(5.7 \%)$.

and feeling unwell within $24 \mathrm{~h}$ of the procedure, severe enough to require hospital admission or emergency room admission after the procedure, with chest-radiographic infiltrates requiring (and resolving with) broad-spectrum antibiotic therapy. Lymphadenitis was defined as fever (temperature $>38.5^{\circ} \mathrm{C}$ ) and feeling unwell within $48 \mathrm{~h}$ of an EBUS procedure including fine needle aspiration of lymph nodes in the absence of new chest-radiographic infiltrates and with either positive cultures from lymph node sampling or chest CT evidence of rapid enlargement of a sampled lymph node after the procedure requiring (and resolving with) broadspectrum antibiotic therapy.

Procedure length was measured with a handheld stopwatch from the time the bronchoscope was inserted into the oropharynx at the start of the procedure to the time the bronchoscope was removed from the oropharynx at procedure completion.

Procedures performed primarily for diagnostic purposes were considered diagnostic if any of the specimens obtained demonstrated a specific diagnosis. A finding of normal lymphocytes on mediastinal lymph node aspiration was also considered diagnostic if confirmed by further testing (i.e. mediastinoscopy or serial imaging revealing adenopathy resolution). Procedures were also considered diagnostic if lymphoma was found on cytology and/or flow cytometry whether or not treatment was started based on this result, or if surgical biopsy was performed as recommended by hematology for confirmation.

\section{Statistical Analysis}

Three metrics were selected a priori as most relevant to the assessment of the effect of trainee participation in the procedures: total procedure time, total sedation used and total complications. In addition, procedural diagnostic rate was also compared. Pneumothorax rates were also compared in the subgroup of procedures including transbronchial biopsy given their association with this complication. The results were analyzed between groups with a standard $t$ or $\chi^{2}$ test as appropriate. Regression analysis was used to model trainee participation, procedure subtype, inpatient versus outpatient status, age, gender, malignant diagnosis and use of clopidogrel on the main outcome measures of procedure time and sedation used (linear models) and occurrence of complications (binary logistic model).

\section{Results}

Eleven hundred consecutive procedures were entered into the database, including 967 flexible bronchoscopies that form the subset for this study. Patient demographics and procedure details are listed in table 1 . A trainee participated in 795 (82.2\%) of the procedures. An interventional pulmonology fellow participated in $66.4 \%$ of the procedures. General pulmonary fellows, critical care fellows and thoracic surgery fellows participated in 328 (33.9\%), $13(1.3 \%)$, and $29(3.0 \%)$ of the procedures respectively; $23.4 \%$ (226) of procedures had a second trainee participate in the procedure, in addition to the interventional pulmonology fellow; $712(73.6 \%)$ of the patients were outpatients and the majority of procedures [951 (98.3\%)] were done in the bronchoscopy suite, with 2 $(0.2 \%)$ being doing in the operating room, and 14 (1.4\%) being done in the critical care unit. Overall, complications occurred in 38 patients (3.9\%), with the most common being pneumothorax: 16 (1.7\%). No deaths occurred.

Main results for the three primary outcome measures can be found in table 2. Significant differences were seen when a trainee participated in the procedure versus when no trainee participated for procedure length [50.81 vs. $32.49 \mathrm{~min}$, difference $18.32 \mathrm{~min}$ (95\% CI 16.04-20.60), $\mathrm{p}$ $=0.001]$, dose of midazolam used [6.34 vs. $5.73 \mathrm{mg}$, dif- 
Table 2. Main results of flexible bronchoscopy

\begin{tabular}{lccc}
\hline Characteristics & $\begin{array}{l}\text { No trainee } \\
(\mathrm{n}=172)\end{array}$ & $\begin{array}{l}\text { Trainee } \\
(\mathrm{n}=795)\end{array}$ & Difference, $\mathrm{p}$ value \\
\hline Total procedure time (mean $\pm \mathrm{SD}), \mathrm{min}$ & $32.49 \pm 13.54$ & $50.81 \pm 13.89$ & $18.32(95 \% \mathrm{CI} 16.04-20.60), \mathrm{p}=0.001$ \\
Propofol used (mean $\pm \mathrm{SD}), \mathrm{mg}$ & $111.60 \pm 88.43$ & $153.08 \pm 103.81$ & $41.48(95 \% \mathrm{CI} 21.81-61.15), \mathrm{p}=0.001$ \\
Midazolam used (mean $\pm \mathrm{SD}), \mathrm{mg}$ & $5.73 \pm 2.92$ & $6.34 \pm 2.81$ & $0.61(95 \%$ CI $0.15-1.08), \mathrm{p}=0.01$ \\
Total complications, $\mathrm{n}$ & $2(1.2 \%)$ & $36(4.5 \%)$ & $3.3 \%, \mathrm{p}=0.048$ \\
\hline
\end{tabular}

Table 3. Flexible bronchoscopy: complication details

\begin{tabular}{llr}
\hline Complications $^{\mathrm{a}}$ & No trainee $(\mathrm{n}=172)$ & Trainee $(\mathrm{n}=795)$ \\
\hline Pneumothorax $^{\mathrm{b}}$ & $0(0 \%)$ & $16(2.0 \%)$ \\
Pneumothorax requiring a chest tube $_{\text {Postbronchoscopic infection (pneumonia or lymphadenitis) }}$ & $0(0 \%)$ & $10(1.3 \%)$ \\
Congestive heart failure & $0(0 \%)$ & $10(1.3 \%)$ \\
Hypoxic respiratory failure & $1(0.6 \%)$ & $3(0.4 \%)$ \\
Hospital admission for COPD exacerbation & $0(0 \%)$ & $2(0.2 \%)$ \\
Myocardial infarction & $1(0.6 \%)$ & $2(0.2 \%)$ \\
Seizure & $0(0 \%)$ & $1(0.1 \%)$ \\
Major bleeding & $0(0 \%)$ & $1(0.1 \%)$ \\
Chipped tooth & $0(0 \%)$ & $1(0.1 \%)$ \\
Total complications $(\mathrm{p}=0.048)^{\mathrm{d}}$ & $0(0 \%)$ & $1(0.1 \%)$ \\
\hline
\end{tabular}

COPD = Chronic obstructive pulmonary disease.

${ }^{a}$ All adverse events listed are serious adverse events, with the exception of a chipped tooth.

$\mathrm{b}$ The majority of the pneumothoraces were related to ENB (1), transbronchial biopsy (9) and peripheral EBUS (4), although there was 1 case of pneumothorax requiring a chest tube related to EBUS-TBNA biopsy of a 10R lymph node (no transbronchial biopsies were performed). One pneumothorax not requiring a chest tube was thought to be related to a bronchoalveolar lavage (although EBUS was used during that procedure, no enlarged lymph nodes were found and no EBUS-TBNA sampling was performed).

${ }^{c}$ Bleeding was caused by trauma to an endobronchial tumor by the EBUS-TBNA bronchoscope (not the needle) and required electrocautery and cold saline for bleeding control.

${ }^{\mathrm{d}}$ Except for total complications $(\mathrm{p}=0.048)$, all other comparisons were nonsignificant $(\mathrm{p}>0.05)$.

ference $0.61 \mathrm{mg}$ (95\% CI 0.15-1.08), $\mathrm{p}=0.01$ ], dose of propofol used [ $153.08 \mathrm{vs} .111 .60 \mathrm{mg}$, difference $41.48 \mathrm{mg}$ (95\% CI 21.81-61.15), $\mathrm{p}=0.001$ ], as well as the frequency of complications [ 4.5 vs. $1.2 \%$, difference $3.3 \% \mathrm{p}=0.048$ ]. The details of complications associated with flexible bronchoscopy are listed in table 3.

Flexible bronchoscopy with a primarily diagnostic intent comprised $786(81.3 \%)$ of the procedures. Overall diagnostic rate was 734/786 (93\%) with no significant differences seen when a trainee participated in the procedure versus when no trainee participated for diagnostic rate $[597 / 644(92.7 \%)$ vs. $135 / 142(95.1 \%)$, difference $2.4 \%, \mathrm{p}=0.3$ ].

Of the procedures involving transbronchial biopsy, ENB and/or peripheral EBUS (procedures with biopsy of the lung parenchyma/peripheral nodules and therefore more likely to have a pneumothorax), more cases of pneumothorax were seen in the trainee group [14/172 (8.1\%) vs. $0 / 36(0 \%)$, difference $8.1 \%, p=0.133$ ] although this was not statistically significant. Cases involving these higher risk techniques were equally distributed between the two groups (table 1). Analysis of all procedures involving EBUS-TBNA [607 (55.2\%) of the 967 procedures] did not find a statistically significant difference between groups for the number of samples taken ( mean \pm SD) per procedure ( $4.42 \pm 1.23$ vs. $4.69 \pm 1.34 ; \mathrm{n}=512$ and 95 respectively).

A linear regression model (ANOVA $\mathrm{p}=0.002, \mathrm{R}^{2}=$ $0.952)$ noted that trainee presence was the most important predictor of procedure length (coefficient $B=26.8, p$ 
$<0.001)$. Trainee presence was also the most important predictor of propofol dose (ANOVA $\mathrm{p}<0.001, \mathrm{R}^{2}=0.114$, coefficient $\mathrm{B}=36.1, \mathrm{p}<0.001)$. Binary logistic regression suggested that the occurrence of complications was significantly related to procedure type $(\mathrm{p}=0.003)$, but presence of trainees did not reach statistical significance $(\mathrm{p}=$ $0.057)$.

\section{Discussion}

This study demonstrates that in an academic interventional pulmonology practice, trainee participation in flexible bronchoscopy procedures can increase procedure time and the amount of sedation required, and can result in increased complications. Our study is the first to demonstrate increased complication rates in bronchoscopy procedures with trainee participation compared to the same procedures without trainee participation. It is also the first study to examine the effect of trainee participation on bronchoscopy procedure time and sedation requirements.

Increased complication rates in bronchoscopy procedures performed by novice bronchoscopists have been demonstrated previously. In a retrospective study from an academic pulmonology practice in the United States, Ouellette [16] revealed that novice bronchoscopists had a complication rate of $3.1 \%$, i.e. significantly higher than the rate of $1.57 \%$ seen in the senior trainees. As in our study, the most common complication was pneumothorax. The complication rate of $4.5 \%$ seen in the trainee group in our study is similar to the complication rate of $3.1 \%$ demonstrated in the novice bronchoscopists in the Ouellette study. The senior trainees in the Ouellette study had a complication rate of $1.57 \%$, which is lower than the $4.5 \%$ seen in our study. This difference could be explained by the more invasive and interventional nature of the bronchoscopies performed in our study. Additionally, our study used a broader complication definition and included some less serious complications in the total complication rates versus only the 'serious complications' being reported in the Ouellette study [16].

The complication rates in our study are consistent with previously reported complication rates [9-16]. Overall complication rates from flexible bronchoscopy have been reported from 0.5 to $11 \%$ and serious complications from 0.8 to $5 \%$, with mortality rates from 0 to $0.17 \%$ [10-16]. There were no deaths in our study.

Oxygen saturation and pulmonary function are negatively affected during bronchoscopy $[17,18]$. It is possible that longer bronchoscopy procedures with increased se- dation requirements could lead to worsened pulmonary impairment, contributing to increased complications such as exacerbations of chronic obstructive pulmonary disease, postbronchoscopic pneumonia and even myocardial infarction and congestive heart failure. The increased procedure time and sedation requirements observed in the trainee group could have contributed to these types of complications. Although the mean total procedure time in our study is longer than in some previous bronchoscopy studies [19-22], these studies did not include the use of additional advanced diagnostic and therapeutic techniques such as peripheral EBUS, ENB and electrocautery.

No difference in diagnostic yield was seen between groups, which contrasts with learning curve studies demonstrating increasing yields with increasing experience [23]. However, this may be explained by the experienced interventional pulmonologist guiding the procedure to ensure adequate sampling. Procedure time and total sedation used were closely related, which is not a surprising finding given that more sedation is required for longer procedures. Based on what we know of the complex field of the motor skill learning theory [24], experts would be expected to perform procedures faster than trainees. The results of this study would suggest that having learners acquire these motor skills by practicing on patients is associated with costs in terms of patient morbidity in addition to probably added financial costs.

Trainees in this study learned bronchoscopy via the apprenticeship model (by practicing on patients) without alternative teaching methods such as a simulation-based training curriculum. Given that our study results support the opinion that patient-based teaching methods for medical procedures result in increased risk for procedure-related morbidity $[1,2]$, other nonpatient-based teaching methods need to be explored. Computer bronchoscopy simulators have been validated as a means of measuring bronchoscopic skills [25-27]. Other studies have demonstrated the bronchoscopy simulator to be a useful tool for enhancing learning [28-30] and improving procedural efficiency [31-33], with effective skill transfer from the simulator to reality $[25,31]$, with studies now focusing on using these validated instruments to evaluate competency $[34,35]$. Use of inanimate and animal models for learning bronchoscopy [33], and the use of simulation-based curricula for learning other medical procedures have also been shown to be effective [36]. Simulation allows for the process of learning to be standardized. High stake scenarios, such as advanced bronchoscopy procedures or cardiac arrest scenarios, can be simulated and repeated as needed in a controlled environment with 
no risk to patients. With simulation-based educational programs demonstrating improved outcomes in central venous catheter insertion [3, 4], laparoscopic surgery [37] and thoracentesis [38], it seems likely that future studies will demonstrate similar improvements in bronchoscopy.

The apprenticeship model has a number of disadvantages for learners. Learning flexible bronchoscopy by practicing on patients introduces significant variability into the learning experience and has been associated with increased learner anxiety $[1,39]$. Learning medical procedures in patient care in a high stress environment can lead to excessive learner activation, resulting in decreased learning retention [40]. Evidence supporting the use of simulation-based curricula in procedural education continues to accumulate [5], as does evidence against the traditional use of patients as practice subjects for trainees learning medical and surgical procedures $[3,4,36-40]$. Our data add further support to the importance of finding new nonpatient-based methods of learning procedural skills.

The study data were obtained from a prospectively collected quality assurance database (as a result there were no missing data points, with the exception of 3 patients in whom follow-up data were not available), however, the retrospective analysis of the study has limitations, including possibly missing some minor complications not apparent after the procedure. We found no differences between groups in terms of age, sex, use of clopidogrel, prevalence of malignancy and number of additional procedures performed, however, because the patients were not randomized there may have been differences between groups not apparent in our analysis. Although there were more inpatients in the no-trainee group, this only serves to strengthen our findings, as we would expect more complications to occur in this sicker patient population.
This study evaluated the procedures performed in the practice of a single interventional pulmonologist. Therefore, the results may not be applicable to all bronchoscopists. It is possible that sedation requirements, procedure time and possibly even the complications noted could be affected by variation in the teaching technique. Given that the trainees in this study participated in all aspects of the procedures, including all biopsy techniques, a more stepwise progression of procedural participation could have affected the outcomes measured. In addition, since senior trainees (interventional pulmonology fellows) were the most common type of learners during these procedures, adverse consequences of more junior trainees may be more pronounced than what was noted in our study. Repeating this study with a prospective, randomized approach with multiple bronchoscopists and a larger sample size from different centers would be ideal.

In summary, this study demonstrates that in an academic interventional pulmonology practice utilizing the apprenticeship model for procedural education, trainee participation in flexible bronchoscopy increases procedure time and the amount of sedation required, and results in increased complications. Considering the negative impact that the apprenticeship model of procedural learning can have on procedural and patient outcomes, it is necessary to modify procedural training, including further investigation into the use of educational curricula using simulation, in order to reduce the burden of procedural learning on patients.

\section{Financial Disclosures and Conflicts of}

The authors have no conflicts of interest to disclose.

\section{References}

1 Silvestri GA: The evolution of bronchoscopy training. Respiration 2008;76:19-20.

2 Lennon M, Zaw NN, Pöpping DM, Wenk M: Procedural complications of central venous catheter insertion. Minerva Anestesiol 2012; 78:1234-1240.

-3 Ma IW, Brindle ME, Ronksley PE, Lorenzetti DL, Sauve RS, Ghali WA: Use of simulationbased education to improve outcomes of central venous catheterization: a systematic review and meta-analysis. Acad Med 2011;86: 1137-1147.

-4 Sekiguchi H, Tokita JE, Minami T, Elsen LA, Mayo PH, Narasimhan M: A pre-rotational, simulation-based workshop improves the safety of central venous catheter insertion: results of a successful internal medicine house staff training program. Chest 2011;140:652-658.

5 Cook DA, Hatala R, Brydges R, Zendejas B, Szostek JH, Wang AT, Erwin PJ, Hamstra SJ: Technology-enhanced simulation for health professions education: a systematic review and meta-analysis. JAMA 2011;306:978-988.

-6 Kessler DO, Auerback M, Pusic M, Tunik GM, Foltin JC: A randomized trial of simulation-based deliberate practice for infant lumbar puncture skills. Simul Healthc 2011;6: 197-203.
7 Gordon CE, Feller-Kopman D, Balk EM, Smetana GW: Pneumothorax following thoracentesis. A systematic review and metaanalysis. Arch Intern Med 2010;170:332-339.

$\checkmark 8$ van der Leeuw RM, Lombarts KM, Arah OA Heineman MJ: A systematic review of the effects of residency training on patient outcomes. BMC Med 2012;10:65.

9 Reinosos MA, Lechin A, Vaon J, Wade L: Complications from flexible bronchoscopy in a training program. JOB 1996;3:177-181.

10 Jin F, Mu D, Chu D, Fu E, Xie Y, Liu T: Severe complications of bronchoscopy. Respiration 2008;76:429-433.
Trainee Impact on Procedural

Complications 
11 Pue CA, Pacht ER: Complications of fiberoptic bronchoscopy at a university hospital. Chest 1995; 107:430-432.

12 Surratt DM, Smiddy JF, Bruber B: Deaths and complications associated with fiberoptic bronchoscopy. Chest 1976;69:747-751.

-13 Facciolongo N, Patelli M, Gasparini S, Lazzari Agli L, Salio M, Simonassi C, Del Prato B, Zanoni P: Incidence of complications in bronchoscopy. Multicentre prospective study of 20,986 bronchoscopies. Monaldi Arch Chest Dis 2009;71:8-14.

14 Colt HG, Matsuo T: Hospital charges attributable to bronchoscopy-related complications in outpatients. Respiration 2001;68:67 72.

15 Sen RP, Walsh TE: Serious complications of fiberoptic bronchoscopy. Chest 1988;94:222.

16 Ouellette D: The safety of bronchoscopy in a pulmonary fellowship program. Chest 2006; 130:1185-1190.

17 Lin CC, Wu JF, Huang WC: Pulmonary function in normal subjects after bronchoalveolar lavage. Chest 1988;93:1049-1053.

18 Tilles D, Coldenheim PD, Cinns UC, Hales CA: Pulmonary function in normal subjects and patients with sarcoidosis after bronchoalveolar lavage. Chest 1986;89:244-248.

19 Herth FJ, Eberhardt R, Vilmann P, Krasnik M, Ernst A: Real-time endobronchial ultrasound guided transbronchial needle aspiration for sampling mediastinal lymph nodes. Thorax 2006;61:795-798.

-20 Tremblay A, Stather DR, MacEachern P, Khalil M, Field SK: A randomized controlled trial of standard vs endobronchial ultrasonography-guided transbronchial needle aspiration in patients with suspected sarcoidosis Chest 2009;136:340-346.

21 Herth FJ, Ernst A, Eberhardt R, Vilmann P, Dienemann H, Krasnik M: Endobronchial ultrasound-guided transbronchial needle aspiration of lymph nodes in the radiologically normal mediastinum. Eur Respir J 2006;28: 910-914.
22 Lee HS, Lee GK, Lee HS, Kim MS, Lee JM, Kim HY, Nam BH, Zo JI, Hwangboo B: Realtime endobronchial ultrasound-guided transbronchial needle aspiration in mediastinal staging of non-small cell lung cancer: how many aspirations per target lymph node station? Chest 2008;134:368-374.

23 Kemp SV, El Batrawy SH, Harrison RN, et al: Learning curves for endobronchial ultrasound using cusum analysis. Thorax 2010;65: 534-538.

24 Magill RA: Motor Learning and Control. Concepts and Applications, ed 9. New York, McGraw-Hill, 2010, pp 235-240.

25 Ost D, DeRosiers A, Britt EJ, Fein AM, Lessier ML, Mehta AC: Assessment of a bronchoscopy simulator. Am J Respir Crit Care Med 2001;164:2248-2255.

26 Stather DR, MacEachern P, Rimmer K, Hergott CA, Tremblay A: Validation of an endobronchial ultrasound simulator: differentiating operator skill level. Respiration 2011;81: 325-332.

27 Konge L, Arendrup H, von Buchwald C, Ringsted C: Using performance in multiple simulated scenarios to assess bronchoscopy skills. Respiration 2011;81:483-490.

28 Colt HG, Crawford SW, Galbraith O: Virtual reality bronchoscopy simulation: a revolution in procedural training. Chest 2001;120:13331339.

29 Blum MG, Powers TW, Sundaresan S: Bronchoscopy simulator effectively prepares junior residents to competently perform basic clinical bronchoscopy. Ann Thorac Surg 2004;78:287-291.

30 Stather DR, MacEachern P, Rimmer K, Hergott CA, Tremblay A: Assessment and learning curve evaluation of endobronchial ultrasound skills following simulation and clinical training. Respirology 2011;16:698-704.

- 31 Stather DR, MacEachern P, Chee A, Dumoulin E, Tremblay A: Evaluation of clinical endobronchial ultrasound skills following clinical versus simulation training. Respirology 2012;17:291-299.

-32 Wahidi MM, Silvestri GA, Coakley RD, Ferguson JS, Shepherd RW, Moses L, Conforti J, Que L, Anstrom KJ, McGuire F, Colt H, Downie GH: A prospective multi-center study of competency metrics and educational interventions in the learning of bronchoscopy among starting pulmonary fellows. Chest 2010;137:10401049.
3 Stather DR, MacEachern P, Chee A, Dumoulin E, Tremblay A: A randomized trial of teaching endobronchial ultrasound: wet lab versus computer simulation. Can Respir J 2012;19:325-330.

- 34 Konge L, Vilmann P, Clementsen P, Annema JT, Ringsted C: Reliable and valid assessment of competence in endoscopic ultrasonography and fine-needle aspiration for mediastinal staging of non-small cell lung cancer. Endoscopy 2012;44:928-933.

35 Davoudi M, Colt HG, Osann KE, Lamb CR, Mullon JJ: Endobronchial ultrasound skills and tasks assessment tool: assessing the validity evidence for a test of endobronchial ultrasound-guided transbronchial needle aspiration operator skill. Am J Respir Crit Care Med 2012;186:773-779.

- 36 Smith CC, Gordon CE, Feller-Kopman D, Huang GC, Weingart SN, Davis RB, Ernst A, Aronson MD: Creation of an innovative inpatient medical procedure service and a method to evaluate house staff competency. J Gen Intern Med 2004;19:510-513.

37 Zendejas B, Cook DA, Bingener J, Huebner M, Dunn WF, Sarr MG, Farley DR: Simulation-based mastery learning improves patient outcomes in laparoscopic inguinal hernia repair: a randomized controlled trial. Ann Surg 2011;254:502-509.

- 38 Duncan DR, Morgenthaler TI, Ryu JH, Daniels CE: Reducing iatrogenic risk in thoracentesis: establishing best practice via experiential training in a zero-risk environment. Chest 2009;135:1315-1320.

-39 Colt HG, Crawford SW, Galbraith O: Virtual reality bronchoscopy simulation: a revolution in procedural training. Chest 2001;120:13331339.

40 Gordon JA: As accessible as a book on a library shelf. The imperative of routine simulation in modern health care. Chest 2012;141:15-16.

41 Stather DR, MacEachern P, Chee A, Tremblay A: Safety of endobronchial ultrasound-guided transbronchial needle aspiration for patients taking clopidogrel: a report of 12 consecutive cases. Respiration 2012;83:330-334. 